\title{
REVIEW
}

\section{Bisphosphonates and bone quality}

\author{
Michael Pazianas ${ }^{1}$, Stefan van der Geest ${ }^{2}$ and Paul Miller ${ }^{3}$ \\ ${ }^{1}$ Nuffield Orthopaedic Centre, Nuffield Department of Orthopaedics, Rheumatology and Musculoskeletal Diseases, \\ The Botnar Research Center, Institute of Musculoskeletal Sciences, Oxford University, Oxford, UK. ${ }^{2}$ HRA Pharma, \\ Paris, France. ${ }^{3}$ Colorado Center for Bone Research, Lakewood, CO, USA.
}

\begin{abstract}
Bisphosphonates (BPs) are bone-avid compounds used as first-line medications for the prevention and treatment of osteoporosis. They are also used in other skeletal pathologies such as Paget's and metastatic bone disease. They effectively reduce osteoclast viability and also activity in the resorptive phase of bone remodelling and help preserve bone micro-architecture, both major determinants of bone strength and ultimately of the susceptibility to fractures. The chemically distinctive structure of each BP used in the clinic determines their unique affinity, distribution/penetration throughout the bone and their individual effects on bone geometry, micro-architecture and composition or what we call 'bone quality'. BPs have no clinically significant anabolic effects. This review will touch upon some of the components of bone quality that could be affected by the administration of BPs.
\end{abstract}

BoneKEy Reports 3, Article number: 529 (2014) | doi:10.1038/bonekey.2014.24

\section{Introduction}

Osteoporosis is the result of inadequate maintenance of the skeleton and by definition it is the deterioration of bone micro-architecture that leads to increased fragility and consequently to increased risk of fracture. ${ }^{1}$ Bisphosphonates (BPs) are a group of anti-resorptive medications that preserve the macro- and micro-architecture of the skeleton and reduce the risk of fracture. As such, they affect the collective properties of what we describe as 'bone quality', which includes bone geometry, micro-architecture and composition. ${ }^{2}$

The strength of any object is determined by its structural and material properties, which require constant maintenance and repair. Bone structure can be maintained via the process of remodelling through discrete cellular units comprised of osteoclasts and osteoblasts, known as basic multicellular units (BMUs). ${ }^{3}$ The rate of the tightly regulated coupling of bone resorption followed by bone formation could be affected by the use of BPs. Individual BPs inhibit bone resorption to various degrees due to differences in their physico-chemical structure, which leads to differences in binding affinity and biochemical potency (mainly through the inhibition of the farnesyl pyrophosphate synthase enzyme in osteoclasts), thus suppressing bone turnover. ${ }^{4}$ The individual characteristics of BPs affect their fluid and tissue concentrations (influenced by the route of administration and dosing regimens), distribution and penetration, as well as tissue release (off-loading), and ultimately their clinical efficacy in fracture prevention. Broadly, BPs are classified as non-nitrogen-containing BPs (etidronate, clodronate and tiludronate), and nitrogen-containing BPs (alendronate, risedronate, ibandronate, pamidronate and zoledronate). The addition of nitrogen in the structure of BPs led to a marked increase in their potency and introduced a new mechanism of action involving primarily the mevalonate pathway and the inhibition of farnesyl pyrophosphate synthase. ${ }^{4}$

Several clinical trials studied the effects of the individual BPs on fracture outcomes, primarily evaluating the effect of BP administration on the risk of vertebral and hip fractures. Non-vertebral fractures, changes in bone mineral density (BMD) and bone turnover markers were often evaluated as secondary end points. Furthermore, the performance of paired bone biopsies in some of these patients enabled the study of several aspects of bone quality and turnover. This review provides an overview of how BP treatments reduce fracture risk, in the context of bone quality.

\section{BP Distribution and Bone Affinity}

Bone is composed of two distinct layers. The outer layer of cortical bone is compact and dense, and allows little space for cell migration or vascular formation. The inner layer of trabecular bone, however, is composed of a rod-like matrix that allows room for marrow, blood vessels and easy cell migration. In the trabecular bone, the BMUs lie on the surface of trabeculae; in the cortical bone they can only start from an existing Haversian or Volkmann's canal and therefore cortical bone could be less accessible to BPs. The binding affinity of

Correspondence: Dr M Pazianas, Nuffield Orthopaedic Centre, Nuffield Department of Orthopaedics, Rheumatology and Musculoskeletal Diseases, The Botnar Research Centre, Institute of Musculoskeletal Sciences, Oxford University, Headington, Oxford OX3 7LD, UK.

E-mail: Michael.Pazianas@ndorms.ox.ac.uk 
individual BPs to hydroxyapatite (influenced by both side chains $\mathrm{R} 1$ and R2, attached to the carbon atom of the P-C-P group) determines their distribution. ${ }^{5,6}$ Their rank order from the BP with the highest hydroxyapatite affinity to that with the lowest is as follows: zoledronate $>$ pamidronate $>$ alendronate $>$ ibandronate $>$ risedronate $>$ etidronate $>$ clodronate..$^{7,8}$ BPs with high affinity bind rapidly to resorbing surfaces that are more abundant in trabecular than in cortical bone, and disappear quickly from the bloodstream and extracellular fluid. BPs with lower affinity are available for longer periods and penetrate more deeply, depositing onto cortical bone and deep within canaliculi. ${ }^{5}$ To a lesser extent, BPs are also deposited onto bone surfaces that are not undergoing active remodelling. ${ }^{9}$ In general, high-affinity compounds tend to concentrate mostly near the surface, whereas low-affinity compounds distribute more equally across the cement/reversal line.$^{10}$ Furthermore, despite the fact that the trabecular bone comprises only $20 \%$ of the total skeletal mass, ${ }^{11}$ BPs overall tend to bind more extensively to trabecular bone, which is more accessible and metabolically active than cortical bone. This may be one of the reasons for the greater reduction of the vertebral fracture risk observed in patients taking BPs, compared with BP-induced reduction in non-vertebral fracture risk, as the vertebrae have a greater trabecular-to-cortical bone ratio.

\section{BP Effects on Bone Cells}

\section{Osteoclasts}

The primary target cell of BPs is the osteoclast. BPs bind to the bone surface and are 'ingested' by osteoclasts during active bone resorption or, in a similar process, are internalised via pinocytosis from the extracellular fluid. ${ }^{12}$ However, secondary to their high affinity to bone relative to other tissues, significant exposure of BPs to non-osteoclastic cells is limited to the initial period immediately following dose administration. Once attached to the bone surface, BPs may only be released during the active resorption process and then could be taken up by osteoclasts. Their efficacy of action is determined by both the quantity of BP absorbed by the osteoclast and the individual potency of each BP in interfering with intracellular processes.

BPs suppress osteoclast activity and zoledronate has been found to have the greatest anti-resorptive potency on the basis of the degree of inhibition of the major target enzyme farnesyl pyrophosphate synthase in osteoclasts. Next in the ranking (in descending order) is risedronate, then ibandronate, alendronate, pamidronate, clodronate and etidronate. ${ }^{4}$ In actively resorbing osteoclasts, non-nitrogen-containing BPs form ATP analogues and induce apoptosis. ${ }^{4}$ In contrast, nitrogen-containing BPs interfere with the mevalonic pathway, disturbing various cell functions and osteoclast capability to digest bone, thereby functionally inactivating the cell. ${ }^{13,14}$ Indeed, inhibition of bone resorption by alendronate or risedronate does not require osteoclast apoptosis. ${ }^{14}$ Following treatment with a nitrogen-containing $\mathrm{BP}$, the number of osteoclasts could stay the same or even increase. ${ }^{15,16}$ In rats treated with a high dose of zoledronate $(0.3 \mathrm{mg}$ per $\mathrm{kg}$ per week) for 13 months, the number of TRAP + mononuclear cells and non-attached osteoclasts increased significantly. ${ }^{17}$ Clinically, long-term alendronate treatment (10 mg daily) in postmenopausal women increased the number of osteoclasts (compared with the placebo group), with the increase being proportional to the cumulative dose. Almost one third of the osteoclasts were described as being giant cells and detached; up to $37 \%$ were apoptotic. The normal-appearing osteoclasts apparently resorbed bone poorly. ${ }^{13}$

\section{Osteoblasts}

In primary osteoblasts/osteoblastic cell lines both nitrogencontaining and non-nitrogen-containing BPs at low concentrations (range $10^{-9}-10^{-6} \mathrm{M}$ ) increased osteoblast proliferation, differentiation and/or mineralisation and inhibited apoptosis. However, at higher concentrations, this trend reversed ${ }^{18}$ and toxic effects could be seen. ${ }^{19}$ Clinically, and in animal studies, ${ }^{20,21}$ bone formation markers are reduced and this is interpreted as a causal consequence of the reduced bone resorption. Generally, although both groups of BPs have been reported to affect osteoblasts, the nitrogen-containing compounds have been shown to be more potent. ${ }^{18}$

Lately, Eph receptors, members of the receptor tyrosine kinase family, have been identified in the osteoblasts. A membrane-bound ligand, the osteoclast-derived ephrin B2 binds to the EphB4 receptor promoting osteoblast differentiation and bone formation. ${ }^{22}$ This is a bidirectional communication and requires cell contact between the osteoclast and a differentiating osteoblast. When the signal is emitted from the osteoblast to the osteoclast, osteoclast differentiation could be suppressed. Moreover, ephrin B1 is also strongly expressed during osteoclast differentiation and has actions similar to ephrin B2. ${ }^{23}$ Alendronate appears to regulate expression of ephrin B1 through the EphB1 andEphB3 receptors on the osteoblast to suppress further osteoblast differentiation. ${ }^{24}$ Furthermore, nitrogen-containing BPs may increase the gene expression and concentrations of the receptor activator of nuclear factor $-\mathrm{kB}$ ligand or have the opposite effects on osteoprotegerin (OPG) (a decoy receptor and competitive inhibitor of receptor activator of nuclear factor- $\mathrm{\kappa B}$ ligand and receptor activator of nuclear factor- $\mathrm{\kappa B}$ interaction), both produced and secreted by osteoblasts. However, the clinical significance of these actions of BPs has not been established. ${ }^{25,26}$

\section{Osteocytes}

Osteocytes are the most abundant bone cells, orchestrating signals affecting the bone remodelling cycle and mineralisation. They are the main source of sclerostin, which, together with DKK1, another inhibitor of the Wnt pathway, is an important negative regulator of bone mass in humans. ${ }^{27}$ Fluoresceintagged risedronate analogues provided evidence that BPs gain access to osteocytes through the canalicular compartment (osteocytic network). BPs were present in osteocytic lacunae in close proximity to vascular channels and were localised to the lacunae of newly embedded osteocytes close to the bone surface. $^{9}$ When fluorescent conjugates of risedronate and analogues of differing affinities were administered to growing rats to visualise BP distribution, the bone mineral surrounding the blood vessels in the cortical bone showed significantly more pronounced florescent labelling with the administration of higher-affinity compounds. However, the lower-affinity analogues showed increased labelling within the osteocyte canalicular network. ${ }^{5}$

In conditions such as micro-damage, mechanical loading, weightlessness or glucocorticoid use that could induce 
apoptosis in osteocytes, BPs have been reported to exert anti-apoptotic effects ${ }^{28,29}$ at concentrations approximately three orders of magnitude lower than those required by the same agents for the promotion of osteoclast apoptosis in vitro. ${ }^{30}$ As in the case of osteoblasts, higher concentrations could become toxic. Furthermore, these properties were also expressed by experimental BP compounds (for example, the R1-amino-substituted derivative of olpadronate IG9402 ${ }^{31}$ ) that do not affect the resorptive activity of osteoclasts. ${ }^{32}$ Therefore, this action of BPs on the lifespan of osteocytes (and osteoblasts) may not be mediated through the mevalonate pathway. Indeed, there has been evidence that the survival signalling is conditional to the involvement of the connexin 43 hemichannels, the opening of which by BPs leads to activation of extracellular signal-regulated kinases followed by calcium influx. ${ }^{33}$ The proportion of sclerostin-positive rat osteocytes is not significantly affected after treatment with alendronate, which does not appear to alter the mechano-sensing function of osteocytes to load. ${ }^{34}$ Clinically, the effects of BPs on the circulating levels of sclerostin are currently under investigation, with two studies reporting conflicting findings. ${ }^{35,36}$

\section{BP Effects on Trabecular/Cortical Bone}

Bone strength correlates directly to bone mass, which suggests that it is the quantity of bone that determines strength. However, the distribution of the mass is equally important in determining bone integrity and its ability to withstand daily compressive and tensile stress. Computer simulations have been useful tools in the assessment of the effects of universal bone mass removal, as seen with bone thinning in ageing, versus focal removal of bone mass in discrete locations, which is seen in a number of bone pathologies including the response to oestrogen deficiency. ${ }^{37-39}$ They revealed that focal defects lead to loss of connectivity within the overall bone structure and compromise bone strength more significantly than universal thinning.

Current anti-resorptive regimens cannot restore lost structure and improvement of micro-architecture, other than by the closing of resorption pits, has not been documented with BP treatment. Furthermore, based on our current knowledge, it is not possible to determine accurately the optimal level of bone turnover suppression, the ideal duration of treatment and the sufficient length of recovery time for bone remodelling to return to the pretreatment levels following withdrawal. In addition, each BP has different effects on the time to onset of action, duration of effects, BMD and level of bone turnover suppression; some of these individual characteristics could be clinically relevant. ${ }^{4,40}$ It has been reported, for example, that the onset ${ }^{41}$ and recovery of bone turnover suppression appeared earlier with risedronate as compared with alendronate. ${ }^{42}$ Also, in a head-to-head clinical trial, an earlier effect of risedronate was observed on the time course to non-vertebral fracture-risk reduction compared with alendronate. ${ }^{43}$

It is estimated that $80 \%$ of fractures are non-vertebral and occur predominantly at cortical sites. ${ }^{44,45}$ The coalescence of BMUs increases cortical pore diameter, increasing the cortical surface area available for remodelling and subsequent removal of bone tissue. In women over the age of 65 years, cortical porosity increases markedly over time. ${ }^{46}$ In old age, as with osteoporosis, Haversian canals in cortical bone can enlarge due to confluent remodelling of BMUs, leading to trabecularization and thinning of the cortex with a subsequent increase in surface area. ${ }^{46,47}$ Trabecular bone also changes; surface area initially increases (due to perforation of plates) and then consequently decreases as trabeculae are lost. ${ }^{48-50}$ Therefore, differences in the distribution and penetration of $\mathrm{BPs}^{4}$ could be of clinical importance, particularly in the cortical bone in which the low surface-to-volume ratio is remodelled at considerably lower rates than in the trabecular bone.

BMD changes only account for part of the reduction in fracture risk following BP administration, as the increases in BMD are not linearly proportional to the fracture-risk reductions. ${ }^{51,52}$ More recently, however, there have been publications suggesting a more robust relationship between zoledronic acid-induced increases in $\mathrm{BMD}$ and fracture-risk reduction as well as an independent strong relationship between the magnitude of suppression in bone turnover markers and fracture-risk reduction. ${ }^{53}$

Bone densitometry does not provide information on the structural characteristics of the skeleton, although images of the shape of the scanned bones or estimates of their size, and hip axis length (which could affect the distribution of bone mass) could be obtained. ${ }^{54}$ Other noninvasive imaging techniques, however, such as micro-computed tomography (CT), peripheral high-resolution quantitative CT and high-resolution magnetic resonance imaging offer, in many aspects, insights on the bone micro-architecture that are even superior to those obtained from standard histomorphometry of iliac crest bone samples. ${ }^{55}$

Both animal and clinical studies have assessed the effect of the four most commonly used nitrogen-containing BPs (alendronate, risedronate, ibandronate and zoledronate) on bone micro-architecture by evaluating standard histomorphometric measurements from bone biopsies. ${ }^{15,56-59}$ A significant decrease in osteoclast activation frequency was observed, which is consistent with a reduction in overall bone turnover. Furthermore, changes in cortical pore area were examined in bone biopsies at baseline and after 5 years of risedronate or placebo treatment in patients with established osteoporosis. ${ }^{50}$ Although pore area was unchanged in the placebo group, an $18-25 \%$ reduction was observed in the risedronate group. Similarly, histomorphometric data from transiliac bone biopsies (24 in total) obtained from postmenopausal osteoporotic women also suggested that porosity in the iliac crest of the cortical bone was reduced significantly after 2-3 years of $10 \mathrm{mg}$ per day alendronate treatment compared with the placebo group. ${ }^{60}$ It is established that cortical bone porosity has profound effects on bone strength, which varies inversely with increasing porosity. ${ }^{61,62}$

The effects of BPs on trabecular bone micro-architecture beyond the classical histomorphometrical assessment have been explored in animal studies. In ovariectomized nonhuman primates, alendronate treatment decreased activation frequency and indices of bone formation to control levels (low dose) or below (high dose); indices of mineralisation did not change. ${ }^{63}$ In ovariectomized aged rats, ibandronate treatment for 12 months resulted in a dose-dependent increase in trabecular bone volume, load to failure (Fmax) and yield load in long bones and vertebrae. ${ }^{64}$ Risedronate treatment for 18 months compared with no treatment prevented trabecular bone loss in the vertebrae of ovariectomized mini pigs. A 4\% difference in bone volume between the groups was also reported. ${ }^{65}$ In clinical studies, non-osteoporotic menopausal women (6-60 months after menopause) underwent a bone 
biopsy at baseline and after they had been treated daily with risedronate $5 \mathrm{mg}$ or with placebo for 1 year. ${ }^{48}$ micro-CT evaluation revealed decreases in bone volume, trabecular thickness and trabecular number, and increases in percent plate, trabecular separation and marrow star volume (a measure of trabecular porosity) in the placebo compared with the risedronate group. Similar findings were reported in postmenopausal osteoporotic women treated daily with $5 \mathrm{mg}$ of risedronate or placebo for 3 years. Paired bone biopsies were performed at the beginning and at the end of treatment. The deterioration observed in a subgroup of high bone turnover untreated patients (trabecular thinning with its structure becoming more rod-like, and the size of the holes in the bone maze increasing) was prevented in those treated with risedronate. ${ }^{49}$ In both, the non-osteoporotic and osteoporotic risedronate studies, standard histomorphometry supported the micro-CT findings. Similarly, single transilial biopsies obtained at the completion of clinical trials in women treated with alendronate for 2 or 3 years yielded comparable results marked by greater bone volume and trabecular thickness and decreased trabecular spacing. ${ }^{59}$ Also, trabecular microarchitecture was better preserved in patients receiving ibandonate orally ( $2.5 \mathrm{mg}$ daily or $20 \mathrm{mg}$ every other day for 12 doses every 3 months) compared with those on placebo when bone biopsies were assessed by histomorphometry or micro-CT. ${ }^{66}$

In the appendicular skeleton, however, the effects of BP treatment are less pronounced, following assessment with high-resolution quantitative CT. One-year treatment with a monthly administration of $150 \mathrm{mg}$ ibandronate to postmenopausal women with either osteopenia or osteoporosis had some beneficial effects on the cortical thickness of the distal tibia but not on the distal radius where BV/TV and trabecular separation (the primary end points of the study) were similar in both the treatment and placebo groups. ${ }^{67}$ Similar results were reported in a study with postmenopausal, osteopenic women treated with the same ibandronate regimen for 2 years. ${ }^{68}$ Alendronate, administered weekly $(70 \mathrm{mg})$ for 2 years in postmenopausal osteoporotic women, improved trabecular number and separation in the distal tibia but had no effects on the distal radius. ${ }^{69}$ When compared with placebo, weekly alendronate treatment in osteopenic women resulted in a longitudinal increase in the volumetric BMD of the tibia, but, again, not of the radius. ${ }^{11,70}$

The difference in the response to BP treatment between these two peripheral sites is interesting and could be explained by their different structures. At least in patients with history of an osteoporotic fracture, this could be due to a difference in the pattern of their micro-architectural destruction at these sites. ${ }^{71}$ At the radius, the pattern is more consistent with trabecular loss characterised by profound reductions in trabecular number and increased network inhomogeneity. At the tibia, however, the cortical losses are predominant with cortical density being more severely affected, whereas the number of trabeculae is mostly preserved.

\section{BP Effects on Bone as a Structural Material}

Type I collagen is the predominant building block of bone and to a great extent determines its structural and biomechanical features. It is modified by intermolecular crosslinking that provides the visco-elasticity necessary for effective stress distribution. This property supports the bone's tensile strength and allows it to resist both traction and shearing forces. ${ }^{72,73}$ The addition of mineral crystals creates a bio-composite that is also able to withstand compression. Newly synthesised, crosslinked collagen differs in maturity when compared with older matrix. Furthermore, the properties of collagen may differ between osteoporotic and healthy individuals. ${ }^{74}$ Crosslinking could affect the mineralisation process and, if defective, could predispose to the formation of microcracks. ${ }^{75}$ This is evidenced by the fact that osteoporotic bone has a reduced mineral content and increased crystallinity.

BPs may directly affect the structural integrity of bone, altering both the matrix proteins and the mineral crystals. BP treatment has been demonstrated to reduce collagen crosslink ratio to premenopausal levels, and possibly reduce crystal size in bone-formation areas. ${ }^{76}$ As these changes were found in areas of new bone formation, it is probable that they affect only a small amount of bone over time. Although small, this effect should not be ignored for osteoporotic bone with thin trabeculae constantly undergoing remodelling, the volume of newly formed bone can constitute a large percentage of the total bone volume. The mechanical behaviour of these thin trabeculae could therefore be substantially altered by BP treatment. In bones mainly consisting of trabecular bone and where the cortex has thinned to the size of trabecular struts, this effect on the material properties may be even more important. Their impact accumulates over time with each deposition of new bone.

The indirect effects of BP treatment on bone mineralisation are related to a reduction in bone turnover, which leads to an increase in the mean age of bone. New matrix begins to mineralise 5-10 days after deposition and the rate of this primary mineralisation can be measured in vivo using double tetracycline labelling. After completion of the cortical osteons or trabecular packets, the slower, ongoing process of secondary mineralisation begins. Therefore, the older the bone package, the higher the degree of mineralisation.

The degree of mineralisation and its distribution is fairly consistent across species, suggesting that normal mineralisation of bone is optimised to deal with the loads encountered. ${ }^{60}$ The trabecular bone of osteoporotic patients is hypo-mineralised, with an increase in BMD distribution, probably due to increased turnover. ${ }^{77,78}$ Risedronate treatment increased overall mineralisation and reduced BMD distribution to normal premenopausal levels. ${ }^{76}$ Further turnover is suppressed as the overall tissue ages and the the degree of mineralisation increases. After 2-3 years of alendronate treatment, mineralisation in iliac crest biopsies was significantly higher and more uniform than with placebo. ${ }^{60}$ It is important, however, to mention that BP treatment may not lead to hyper-mineralisation of the bone tissue. Instead, a greater number of BMUs achieve their full mineralisation potential allowing for an increase in overall tissue mineralisation and BMD at an organ level. ${ }^{79}$

\section{BPs and Micro-crack Formation}

Micro-cracks are a natural functional adaptation, occurring in bone under normal loading forces. The elastic properties of bone enable energy absorption but cracks occur if the material fails. Osteocyte cell processes form an extensive network that 
runs within canaliculi throughout the bone matrix. A micro-crack in the bone will inevitably rupture one or more osteocyte cellular processes, causing the apoptosis of the osteocyte. ${ }^{80}$ This is thought to release cytokines to attract the cells involved in creating a new BMU, thus leading to targeted remodelling. Treatment with BPs could be detrimental by affecting two different stages of the repair process. First, they could prevent the apoptosis of osteocytes and thus the signalling pathway for targeted remodelling could be disrupted. Second, BPs reduce osteoclast activity and so indirectly reduce the number of new BMUs. It has been reported that in mature female beagle dogs, BP treatment increases the total number of micro-cracks, whereas other anti-resorptive agents such as raloxifene, which are significantly weaker inhibitors of osteoclast activity, increase the length of micro-cracks instead. ${ }^{81}$ However, greater damage accumulation could occur after BP treatment than by other anti-resorptive agents, because of a nonlinear relationship with the degree of suppression by BPs. ${ }^{82}$

Micro-cracks can occur at any skeletal site but are more frequently seen in the trabecular bone, and in particular in the lumbar spine. In a healthy skeleton, crack deflection and uncracked bone-ligament bridging occur to toughen cortical bone, preserving the geometry of the bone and preventing micro-cracks from growing large enough to lead to catastrophic failure. Interestingly, in prolonged suppression of bone remodelling during treatment with a $\mathrm{BP}$, there is evidence that micro-damage accumulation and repair reach a new level of balance that prevents damaged areas from extending further. ${ }^{83,84}$

There is also the possibility that changes in the bone material properties following treatment with BPs will make the bone more susceptible to micro-damage. BPs allow for the formation and accumulation of advanced glycation end products, ${ }^{85,86}$ which are associated with more brittle bones. ${ }^{87,88}$ Advanced glycation end products increased by up to $50 \%$ after 1 year of BP treatment in an animal model, but it is not clear whether this large increase occurs only in the fraction of the bone that is replaced each year, or within the pre-existing bone matrix that is not replaced. ${ }^{89}$ Another possible contributor could be the increased mineralisation that follows BP treatment, leading to stiffer tissue but whose deterioration may increase micro-crack initiation. The extent to which BPs reduce toughness (the ability of the material to absorb energy) varies with the individual BP structure, bone distribution, dose and duration of treatment. Alendronate, for example, allows for more mineralisation than risedronate. An increased rate of micro-cracks was demonstrated in vertebrae from beagles treated with alendronate when they were loaded in cyclic fatigue. Risedronate treatment resulted in micro-damage similar to saline administration. ${ }^{90}$ During ibandronate treatment, the bone retains its capacity for repair and bone mineralisation is not adversely affected..$^{91}$ It has been suggested that alendronate reduces the threshold for the initiation of new micro-cracks as a possible explanation. In summary, micro-damage accumulation occurs in conditions of significantly reduced bone remodelling, including treatment with BPs, and is more pronounced in trabecular than cortical bone structures. Although BPs are associated with a decline in bone toughness, it is thought that micro-damage is not a cause. $^{89}$

Interestingly, in bone exposed to BP treatment, neither a relationship between reduced toughness and changes in micro- damage, mineralisation or collagen crosslinking has been demonstrated nor have any changes in toughness or microcrack accumulation in BP-treated patients been confirmed. ${ }^{89}$ Furthermore, in animal models, despite increased microdamage density relative to controls, ${ }^{84}$ both the whole-bone strength and the stiffness (a property of a structure referring to its rigidity) were increased. ${ }^{92}$ These positive effects of BP treatment have been attributed to increased tissue mineralisation, and maintenance of bone mass and architecture including trabecular number, thickness and connectivity. ${ }^{92}$

\section{BP Effects on Bone Biomechanics}

Study of the biomechanics of bone is hampered by methodological difficulties. Bone biopsies from patients treated with BPs are difficult to obtain and biomechanical testing destroys valuable specimens. Estimates of human bone strength have been reported on the basis of finite element analysis of quantitative $\mathrm{CT}$ and recently on biomechanical $\mathrm{CT}$ (BCT). BCT could be described as the fusion of clinical CT imaging, biomechanics and the technique of finite element analysis. It provides estimates of femoral and vertebral strength that are far superior to those provided by quantitative CTalone. ${ }^{93}$ In clinical studies, alendronate increased vertebral strength in postmenopausal Japanese women at 3 months ${ }^{94}$ and at 6 months in another group of osteoporotic postmenopausal women of white or Hispanic origin. ${ }^{95}$ Femoral strength was increased in postmenopausal osteoporotic women after 2 years of treatment with alendronate. ${ }^{96}$ Similar results were found in both the hip and spine of predominantly white osteopenic/osteoporotic patients after a monthly administration of oral ibandronate for a year. $^{97}$

Bone indentation testing provides the opportunity for direct in vivo measurements of the mechanical properties of bone tissue. ${ }^{98}$ Nano-indentation testing in rats showed that risedronate treatment increased significantly the structural bone strength. ${ }^{99}$ In an ovine model of osteoporosis, zoledronate increased indentation modulus (a measure of tissue stiffness) and hardness (a measure of inelastic properties). ${ }^{100}$ In humans, transiliac bone biopsies obtained from 32 postmenopausal osteoporotic women treated with oral alendronate $(10 \mathrm{mg}$ daily or $70 \mathrm{mg}$ weekly) for $6.4 \pm 2.0$ years and 22 age-matched untreated postmenopausal osteoporotic women were assessed by Vickers indentation tests. Cortical and trabecular micro-hardness and crystallinity were lower in the untreated patients. Also, after 3 years of treatment, the changes in material properties were not dependent on the duration of the treatment. However, the decrease in local mechanical properties may not be specific to alendronate. ${ }^{101}$ Lately, a micro-indentation technique applied in the cortical bone of tibia allows direct estimation of bone material strength in patients. Initial findings suggest that it is superior to bone densitometry. When it was used in 27 women with osteoporosis-related fractures and in eight controls of comparable ages, the discrimination between case and controls was precise. ${ }^{75}$

In a number of studies, in alendronate-treated animals, both bone volume and bone strength were no different from those in the controls. In normal mature non-osteopenic male and female beagle dogs, a 3-year alendronate administration at doses up to fivefold the clinical dose recommended for osteoporosis treatment did not alter bone strength. ${ }^{102}$ Bone strength was also 
preserved in growing female mini pigs treated with alendronate for a year. ${ }^{103}$ In adult female ovariectomized baboons, a 2-year treatment with alendronate increased the bone strength. ${ }^{63}$ In rats, alendronate treatment for 6 months (started 4 months after ovariectomy) preserved the compressive strength of lumbar vertebrae. ${ }^{104}$ Furthermore, alendronate administered throughout skeletal growth, maturation and ageing in male and female rats, increased the bone mechanical properties. ${ }^{105}$ Ovariectomized mini pigs were studied following treatment with risedronate or placebo. The vertebral normalised maximum load (strength) and normalised stiffness were both significantly higher in the high-dose risedronate $(2.5 \mathrm{mg}$ per $\mathrm{kg}$ ) group as compared with the placebo group. ${ }^{65}$ Bone volume measured by micro-CT alone explained $76 \%$ of the variability of the bone strength, and the combination of bone volume and architectural variables explained $>90 \%$ of the strength. These findings showed that risedronate preserved vertebral trabecular architecture in this animal model, and that bone strength was tightly coupled to bone mass and architecture. Also, following 1 year of treatment with alendronate or risedronate in a dog model, the ultimate load ${ }^{106}$ and stiffness ${ }^{107}$ of the vertebrae were significantly higher in the BP-treated groups compared with controls. Finally, in aged ovariectomized rats, high dose of risedronate or ibandronate improved strength (bone mass and architecture as well) but not tissue material properties. ${ }^{108}$

Relatively small increases in bone volume have an important impact on bone strength because when trabeculae are thin the resorbing activity of the BMU, likened to excavating a trench across the bone surface, can have two important biomechanical consequences. If the resorption depth is greater than the diameter of the trabecular strut, the strut will be perforated or disconnected. This has implications for the strength of the network to which the strut was connected, because the buckling load is inversely related to the effective length of the support. If the resorption depth does not result in disconnection, the existence of the resorption pit itself results in an increase in the stress on adjacent bone; a phenomenon known as the stress-riser effect. ${ }^{109}$ Thus, reducing turnover of osteoporotic or thin trabecular bone adds only a tiny amount of bone, but is likely to result in a relatively large improvement in biomechanical function.

The contribution of trabecular bone-to-bone strength is clearly dependent on the amount of trabecular bone at specific locations, and the role of the trabecular micro-architecture probably increases in importance with progressive bone loss. Vertebrae have high trabecular bone content, and in end-stage osteoporosis, the cortex can become as thin as trabeculae. Bone loss can affect the structure differentially, depending on the amount of bone present. The change in trabecular bone structure is dependent on bone volume in a non-linear manner. At low bone volumes, for example, trabecular thickness and separation change at much greater rates than at higher bone volumes. This suggests that the structural integrity of trabecular bone may become rapidly compromised when bone volume falls below a critical value. ${ }^{110}$ The impact of micro-architecture preservation during BP treatment is therefore dependent on the quality of the trabecular bone at the start of treatment.

The contribution of changes in cortical bone to whole-bone strength is also difficult to study and depends on cortical thickness and on the amount and distribution of porosity, neither of which are uniform. A $4 \%$ rise in porosity increases crack propagation through bone by $84 \%$. An increase in porosity from 4 to $10 \%$ more than halves the peak stress that can be tolerated by bone before fracture, and an increase in porosity from 4 to $20 \%$ results in a threefold reduction in the ability of bone to deform without cracking. Both porosity and pore size are significantly related to tensile and shear fracture strength, and there is a nonlinear relationship between porosity and pore size for tensile fracture toughness. ${ }^{111}$ The reduction in cortical porosity observed in the iliac crest biopsies of women treated with alendronate and risedronate, ${ }^{50,60}$ therefore, is likely to have a positive effect on the biomechanics of cortical bone at the iliac crest, although cortical bone from the iliac crest provides only limited information on the biomechanics of cortical bone in the hip.

\section{Summary}

BPs are effective in reducing the risk of osteoporotic fractures. They prevent further deterioration of the bone microarchitecture and preserve the bone strength despite the fact that they increase mineralisation and reduce the ability to absorb energy, which could result in accumulation of micro-cracks. There are recognisable differences between the different BP compounds, including but not limited to bone affinity/detachment, distribution and potency, which determines the degree of suppression of bone turnover. The clinical significance of these differences remains to be established. However, a clearer understanding of these differences among clinicians will help in tailoring treatment for individual patients.

\section{Conflict of Interest}

Michael Pazianas has received consultancy fees from Warner Chilcott. Stefan van der Geest is an ex-employee of Procter \& Gamble. Paul Miller has received research grants from Warner Chilcott, Genentech, Eli Lilly, Merck \& Co, Novartis and Amgen, and speaker and consultancy fees from Warner Chilcott, Eli Lilly, Merck \& Co, Novartis, Amgen, Genentech and GlaxoSmithKline.

\section{Acknowledgements}

We thank Excerpta Medica for their administrative contribution.

\section{References}

1. NIH Consensus Development Panel on Osteoporosis Prevention, Diagnosis, and Therapy. Osteoporosis prevention, diagnosis, and therapy. JAMA 2001;285:785-795

2. Seeman E, Delmas PD. Bone quality: the material and structural basis of bone strength and fragility. N Engl J Med 2006;354:2250-2261

3. Martin TJ, Seeman E. Bone remodelling: its local regulation and the emergence of bone fragility. Best Pract Res Clin Endocrinol Metab 2008;22:701-722.

4. Russell RG, Watts NB, Ebetino FH, Rogers MJ. Mechanisms of action of bisphosphonates: similarities and differences and their potential influence on clinical efficacy. Osteoporos Int 2008;19:733-759.

5. Roelofs AJ, Stewart CA, Sun S, Błażewska KM, Kashemirov BA, McKenna CE et al. Influence of bone affinity on the skeletal distribution of fluorescently labeled bisphosphonates in vivo. $J$ Bone Miner Res 2012;27:835-847.

6. Russell RG. Bisphosphonates: the first 40 years. Bone 2011;49:2-19.

7. Nancollas GH, Tang R, Phipps RJ, Henneman Z, Gulde S, Wu W et al. Novel insights into actions of bisphosphonates on bone: differences in interactions with hydroxyapatite. Bone 2006:38:617-627.

8. Lawson MA, Xia Z, Barnett BL, Triffitt JT, Phipps RJ, Dunford JE et al. Differences between bisphosphonates in binding affinities for hydroxyapatite. J Biomed Mater Res B Appl Biomater 2010;92:149-155. 
9. Roelofs AJ, Coxon FP, Ebetino FH, Lundy MW, Henneman ZJ, Nancollas GH et al. Fluorescent risedronate analogues reveal bisphosphonate uptake by bone marrow monocytes and localization around osteocytes in vivo. J Bone Miner Res 2010;25:606-616.

10. Turek J, Ebetino FH, Lundy MW, Sun S, Kashemirov BA, McKenna CE et al. Bisphosphonate binding affinity affects drug distribution in both intracortical and trabecular bone of rabbits. Calcif Tissue Int 2012:90:202-210.

11. Seeman E. Bone morphology in response to alendronate as seen by high-resolution computed tomography: through a glass darkly. J Bone Miner Res 2010;25: 2553-2557, Erratum in: J Bone Miner Res 2011;26(2):439.

12. Pazianas $M$, Russell RG. Potential therapeutic effects of oral bisphosphonates on the intestine. Ann N Y Acad Sci 2011;1240:E19-E25.

13. Weinstein RS, Roberson PK, Manolagas SC. Giant osteoclast formation and long-term oral bisphosphonate therapy. N Engl J Med 2009;360:53-62.

14. Halasy-Nagy JM, Rodan GA, Reszka AA. Inhibition of bone resorption by alendronate and risedronate does not require osteoclast apoptosis. Bone 2001;29:553-559.

15. Chavassieux PM, Arlot ME, Reda C, Wei L, Yates AJ, Meunier PJ. Histomorphometric assessment of the long-term effects of alendronate on bone quality and remodeling in patients with osteoporosis. J Clin Invest 1997;100:1475-1480.

16. Yang Li C, Majeska RJ, Laudier DM, Mann R, Schaffler MB. High-dose risedronate treatment partially preserves cancellous bone mass and microarchitecture during long-term disuse. Bone 2005;37:287-295

17. Kuroshima S, Go VA, Yamashita J. Increased numbers of nonattached osteoclasts after long-term zoledronic acid therapy in mice. Endocrinology 2012;153:17-28.

18. Bellido T, Plotkin LI. Novel actions of bisphosphonates in bone: preservation of osteoblast and osteocyte viability. Bone 2011;49:50-55

19. Pozzi S, Vallet S, Mukherjee S, Cirstea D, Vaghela N, Santo L et al. High-dose zoledronic acid impacts bone remodeling with effects on osteoblastic lineage and bone mechanical properties. Clin Cancer Res 2009;15:5829-5839.

20. Idris Al, Rojas J, Greig IR, Van't Hof RJ, Ralston SH. Aminobisphosphonates cause osteoblast apoptosis and inhibit bone nodule formation in vitro. Calcif Tissue Int 2008;82: 191-201.

21. Tobias JH, Chow JW, Chambers TJ. 3-Amino-1-hydroxypropylidine-1-bisphosphonate (AHPrBP) suppresses not only the induction of new, but also the persistence of existing bone-forming surfaces in rat cancellous bone. Bone 1993;14:619-623.

22. Zhao C, Irie N, Takada $\mathrm{Y}$, Shimoda $\mathrm{K}$, Miyamoto $\mathrm{T}$, Nishiwaki $\mathrm{T}$ et al. Bidirectional ephrinB2-EphB4 signaling controls bone homeostasis. Cell Metab 2006;4:111-121.

23. Matsuo K, Otaki N. Bone cell interactions through Eph/ephrin: bone modeling, remodeling and associated diseases. Cell Adh Migr 2012;6:148-156.

24. Shimizu E, Tamasi J, Partridge NC. Alendronate affects osteoblast functions by crosstalk through EphrinB1-EphB. J Dent Res 2012;91:268-274.

25. Eslami B, Zhou S, Van Eekeren I, LeBoff MS, Glowacki J. Reduced osteoclastogenesis and RANKL expression in marrow from women taking alendronate. Calcif Tissue Int 2011;88:272-280.

26. Fujita H, Kurokawa K, Ogino T, Ono M, Yamamoto M, Oka T et al. Effect of risedronate on osteoblast differentiation, expression of receptor activator of NF- $\mathrm{KB}$ ligand and apoptosis in mesenchymal stem cells. Basic Clin Pharmacol Toxicol 2011:109:78-84

27. Monroe DG, McGee-Lawrence ME, Oursler MJ, Westendorf JJ. Update on Wnt signaling in bone cell biology and bone disease. Gene 2012;492:1-18

28. Aguirre JI, Plotkin LI, Stewart SA, Weinstein RS, Parfitt AM, Manolagas SC et al. Osteocyte apoptosis is induced by weightlessness in mice and precedes osteoclast recruitment and bone loss. J Bone Miner Res 2006:21:605-615.

29. Bonewald LF. Osteocytes as dynamic, multifunctional cells. Ann N Y Acad Sci 2007;1116:281-290.

30. Hughes DE, Wright KR, Uy HL, Sasaki A, Yoneda T, Roodman GD et al. Bisphosphonates promote apoptosis in murine osteoclasts in vitro and in vivo. J Bone Miner Res 1995;10: 1478-1487.

31. Van Beek E, Löwik C, Que I, Papapoulos S. Dissociation of binding and antiresorptive properties of hydroxybisphosphonates by substitution of the hydroxyl with an amino group. J Bone Miner Res 1996;11:1492-1497.

32. Plotkin LI, Weinstein RS, Parfitt AM, Roberson PK, Manolagas SC, Bellido T. Prevention of osteocyte and osteoblast apoptosis by bisphosphonates and calcitonin. J Clin Invest 1999:104:1363-1374.

33. Plotkin LI, Manolagas SC, Bellido T. Dissociation of the pro-apoptotic effects of bisphosphonates on osteoclasts from their anti-apoptotic effects on osteoblasts/osteocytes with novel analogs. Bone 2006:39:443-452.

34. Macias BR, Swift JM, Nilsson MI, Hogan HA, Bouse SD, Bloomfield SA. Simulated resistance training, but not alendronate, increases cortical bone formation and suppresses sclerostin during disuse. J Appl Physiol 2012;112:918-925.

35. Gatti D, Viapiana O, Adami S, Idolazzi L, Fracassi E, Rossini M. Bisphosphonate treatment of postmenopausal osteoporosis is associated with a dose dependent increase in serum sclerostin. Bone 2012;50:739-742.

36. Chung YE, Lee SH, Lee SY, Kim SY, Kim HH, Mirza FS et al. Long-term treatment with raloxifene, but not bisphosphonates, reduces circulating sclerostin levels in postmenopausal women. Osteoporos Int 2012;23:1235-1243.

37. Borah B, Gross GJ, Dufresne TE, Smith TS, Cockman MD, Chmielewski PA et al. Three-dimensional microimaging (MRmicrol and microCT), finite element modeling, and rapid prototyping provide unique insights into bone architecture in osteoporosis. Anat Rec 2001;265:101-110.
38. Aaron JE, Makins NB, Sagreiya K. The microanatomy of trabecular bone loss in normal aging men and women. Clin Orthop Relat Res 1987;215:260-271.

39. Van der Linden JC, Homminga J, Verhaar JA, Weinans H. Mechanical consequences of bone loss in cancellous bone. J Bone Miner Res 2001;16:457-465.

40. Rosen CJ, Hochberg MC, Bonnick SL, McClung M, Miller P, Broy S et al. Fosamax Actone Comparison Trial Investigators. Treatment with once-weekly alendronate $70 \mathrm{mg}$ compared with once-weekly risedronate $35 \mathrm{mg}$ in women with postmenopausal osteoporosis: a randomized double-blind study. J Bone Miner Res 2005;20:141-151.

41. Allen MR, Turek JJ, Phipps RJ, Burr DB. Greater magnitude of turnover suppression occurs earlier after treatment initiation with risedronate than alendronate. Bone 2011;49: 128-132.

42. Fuchs RK, Phipps RJ, Burr DB. Recovery of trabecular and cortical bone turnover following discontinuation of risedronate and alendronate therapy in ovariectomized rats. J Bone Mine Res 2008;23:1689-1697.

43. Lindsay R, Watts NB, Lange JL, Delmas PD, Silverman SL. Effectiveness of risedronate and alendronate on nonvertebral fractures: an observational study through 2 years of therapy. Osteoporos Int 2013:24:2345-2352, Erratum in: Osteoporos Int 2013;24:2375-6.

44. Augat $\mathrm{P}, \mathrm{Sch}$ rlemmer $\mathrm{S}$. The role of cortical bone and its microstructure in bone strength. Age Ageing 2006:35(Suppl 2):ii27-ii31.

45. Sornay-Rendu E, Boutroy S, Munoz F, Delmas PD. Alterations of cortical and trabecular architecture are associated with fractures in postmenopausal women, partially independent of decreased BMD measured by DXA: the OFELY study. J Bone Miner Res 2007:22:425-433.

46. Zebaze RM, Ghasem-Zadeh A, Bohte A, Iuliano-Burns S, Mirams M, Price Rl et al. Intracortical remodelling and porosity in the distal radius and post-mortem femurs of women: a cross-sectional study. Lancet 2010;375:1729-1736.

47. Foldes J, Parfitt AM, Shih MS, Rao DS, Kleerekoper M. Structural and geometric changes in iliac bone: relationship to normal aging and osteoporosis. J Bone Miner Res 1991;6:759-766.

48. Dufresne TE, Chmielewski PA, Manhart MD, Johnson TD, Borah B. Risedronate preserves bone architecture in early postmenopausal women in 1 year as measured by threedimensional microcomputed tomography. Calcif Tissue Int 2003:73:423-432.

49. Borah B, Dufresne TE, Chmielewski PA, Johnson TD, Chines A, Manhart MD. Risedronate preserves bone architecture in postmenopausal women with osteoporosis as measured by three-dimensional microcomputed tomography. Bone 2004:34:736-746.

50. Borah B, Dufresne T, Nurre J, Phipps R, Chmielewski P, Wagner L et al. Risedronate reduces intracortical porosity in women with osteoporosis. J Bone Miner Res 2010;25:41-47.

51. Watts NB, Cooper C, Lindsay R, Eastell R, Manhart MD, Barton IP et al. Relationship between changes in bone mineral density and vertebral fracture risk associated with risedronate: greater increases in bone mineral density do not relate to greater decreases in fracture risk. $J$ Clin Densitom. 2004, Fall 7:255-261.

52. Delmas PD, Seeman E. Changes in bone mineral density explain little of the reduction in vertebral or nonvertebral fracture risk with anti-resorptive therapy. Bone 2004:34:599-604

53. Jacques RM, Boonen S, Cosman F, Reid IR, Bauer DC, Black DM et al. Relationship of changes in total hip bone mineral density to vertebral and nonvertebral fracture risk in women with postmenopausal osteoporosis treated with once-yearly zoledronic acid $5 \mathrm{mg}$ : the HORIZON-Pivotal Fracture Trial (PFT). J Bone Miner Res 2012;27:1627-1634.

54. Jacques RM, Boonen S, Cosman F, Reid IR, Bauer DC, Black DM et al. Relationship of changes in total hip bone mineral density to vertebral and nonvertebral fracture risk in women with postmenopausal osteoporosis treated with once-yearly zoledronic acid $5 \mathrm{mg}$ : the HORIZON-Pivotal Fracture Trial (PFT). J Bone Miner Res 2012;27:1627-1634.

55. Miller PD. Bone strength and surrogate markers: the first, second, and third fiddle. J Bone Miner Res 2012;27:1623-1626.

56. Recker RR, Delmas PD, Halse J, Reid IR, Boonen S, García-Hernandez PA et al. Effects of intravenous zoledronic acid once yearly on bone remodeling and bone structure. JBone Mine Res 2008;23:6-16.

57. Eriksen EF, Melsen F, Sod E, Barton I, Chines A. Effects of long-term risedronate on bone quality and bone turnover in women with postmenopausal osteoporosis. Bone 2002;31: 620-625.

58. Recker RR, Ste-Marie LG, Langdahl B, Czerwinski E, Bonvoisin B, Masanauskaite D et al. Effects of intermittent intravenous ibandronate injections on bone quality and microarchitecture in women with postmenopausal osteoporosis: the DIVA study. Bone 2010;46:660-665

59. Recker R, Masarachia P, Santora A, Howard T, Chavassieux P, Arlot M etal. Trabecular bone microarchitecture after alendronate treatment of osteoporotic women. Curr Med Res Opin 2005;21:185-194, Erratum in: Curr Med Res Opin 2005;21(2):324.

60. Roschger $P$, Rinnerthaler S, Yates J, Rodan GA, Fratzl P, Klaushofer K. Alendronate increases degree and uniformity of mineralization in cancellous bone and decreases the porosity in cortical bone of osteoporotic women. Bone 2001;29:185-191.

61. Martin RB. Porosity and specific surface of bone. Crit Rev Biomed Eng 1984;10:179-222.

62. McCalden RW, McGeough JA, Barker MB, Court-Brown CM. Age-related changes in the tensile properties of cortical bone. The relative importance of changes in porosity, mineralization, and microstructure. J Bone Joint Surg Am 1993;75:1193-1205.

63. Balena R, Toolan BC, Shea M, Markatos A, Myers ER, Lee SC et al. The effects of 2-year treatment with the aminobisphosphonate alendronate on bone metabolism, bone histomorphometry, and bone strength in ovariectomized nonhuman primates. J Clin Invest 1993:92:2577-2586.

64. Bauss F, Lalla S, Endele R, Hothorn LA. Effects of treatment with ibandronate on bone mass, architecture, biomechanical properties, and bone concentration of ibandronate in ovariectomized aged rats. J Rheumatol 2002;29:2200-2208. 
65. Borah B, Dufresne TE, Chmielewski PA, Gross GJ, Prenger MC, Phipps RJ. Risedronate preserves trabecular architecture and increases bone strength in vertebra of ovariectomized minipigs as measured by three-dimensional microcomputed tomography. J Bone Miner Res 2002:17:1139-1147.

66. Recker RR, Ste-Marie LG, Langdahl B, Masanauskaite D, Ethgen D, Delmas PD. Oral ibandronate preserves trabecular microarchitecture: micro-computed tomography findings from the oral iBandronate Osteoporosis vertebral fracture trial in North America and Europe study. J Clin Densitom 2009;12:71-76.

67. Bock O, Börst H, Beller G, Armbrecht G, Degner C, Martus P et al. Impact of oral ibandronate $150 \mathrm{mg}$ once monthly on bone structure and density in post-menopausal osteoporosis or osteopenia derived from in vivo $\mu \mathrm{CT}$. Bone 2012;50:317-324.

68. Chapurlat RD, Laroche M, Thomas T, Rouanet S, Delmas PD, de Vernejoul MC. Effect of oral monthly ibandronate on bone microarchitecture in women with osteopenia-a randomized placebo-controlled trial. Osteoporos Int 2012;24:311-320.

69. Rizzoli R, Chapurlat RD, Laroche JM, Krieg MA, Thomas T, Frieling I et al. Effects of strontium ranelate and alendronate on bone microstructure in women with osteoporosis. Results of a 2-year study. Osteoporos Int 2012:23:305-315.

70. Burghardt AJ, Kazakia GJ, Sode M, de Papp AE, Link TM, Majumdar S. A longitudinal HR-pQCT study of alendronate treatment in postmenopausal women with low bone density: relations among density, cortical and trabecular microarchitecture, biomechanics, and bone turnover. J Bone Miner Res 2010;25:2558-2571, Erratum in: J Bone Miner Res 2011;26(2):439.

71. Stein EM, Liu XS, Nickolas TL, Cohen A, Thomas V, McMahon DJ et al. Abnormal microarchitecture and stiffness in postmenopausal women with ankle fractures. J Clin Endocrinol Metab 2011;96:2041-2048.

72. Gao H, Ji B, Jager IL, Arzt E, Fratzl P. Materials become insensitive to flaws at nanoscale: lessons from nature. Proc Natl Acad Sci USA 2003;100:5597-5600

73. Jäger I, Fratzl P. Mineralized collagen fibrils: a mechanical model with a staggered arrangement of mineral particles. Biophys J. 2000;79:1737-1746.

74. Saito M, Marumo K. Collagen cross-links as a determinant of bone quality: a possible explanation for bone fragility in aging, osteoporosis, and diabetes mellitus. Osteoporos Int 2010;21:195-214

75. Diez-Perez A, Güerri R, Nogues X, Cáceres E, Peña MJ, Mellibovsky L et al. Microindentation for in vivo measurement of bone tissue mechanical properties in humans. J Bone Miner Res 2010;25:1877-1885.

76. Durchschlag E, Paschalis EP, Zoehrer R, Roschger P, Fratzl P, Recker R et al. Bone material properties in trabecular bone from human iliac crest biopsies after 3- and 5-year treatment with risedronate. J Bone Miner Res 2006;21:1581-1590.

77. Roschger P, Fratzl P, Eschberger J, Klaushofer K. Validation of quantitative backscattered electron imaging for the measurement of mineral density distribution in human bone biopsies. Bone 1998;23:319-326

78. Roschger P, Gupta HS, Berzlanovich A, Ittner G, Dempster DW, Fratzl P et al. Constant mineralization density distribution in cancellous human bone. Bone 2003:32:316-323

79. Fuchs RK, Faillace ME, Allen MR, Phipps RJ, Miller LM, Burr DB. Bisphosphonates do not alter the rate of secondary mineralization. Bone 2011:49:701-705

80. Cardoso L, Herman BC, Verborgt O, Laudier D, Majeska RJ, Schaffler MB. Osteocyte apoptosis controls activation of intracortical resorption in response to bone fatigue. $J$ Bone Miner Res 2009;24:597-605.

81. Allen MR, Iwata K, Sato M, Burr DB. Raloxifene enhances vertebral mechanical properties independent of bone density. Bone 2006:39:1130-1135

82. Burr D. Microdamage and bone strength. Osteoporosis Int 2003;14:67-72.

83. Allen MR, Burr DB. Three years of alendronate treatment results in similar levels of vertebral microdamage as after one year of treatment. $J$ Bone Miner Res 2007:22:1759-1765.

84. Green JO, Diab T, Allen MR, Vidakovic B, Burr DB, Guldberg RE. Three years of alendronate treatment does not continue to decrease microstructural stresses and strains associated with trabecular microdamage initiation beyond those at 1 year. Osteoporos Int 2012;23: 2313-2320.

85. Allen MR, Gineyts E, Leeming DJ, Burr DB, Delmas PD. Bisphosphonates alter trabecular bone collagen cross-linking and isomerization in beagle dog vertebra. Osteoporos Int 2008;19:329-337.

86. Tang SY, Allen MR, Phipps R, Burr DB, Vashishth D. Changes in non-enzymatic glycation and its association with altered mechanical properties following 1-year treatment with risedronate or alendronate. Osteoporos Int 2009;20:887-894.

87. Saito M, Mori S, Mashiba T, Komatsubara S, Marumo K. Collagen maturity, glycation inducedpentosidine, and mineralization are increased following 3-year treatment with incadronate in dogs. Osteoporos Int 2008;19:1343-1354.
88. Tang SY, Zeenath U, Vashishth D. Effects of non-enzymatic glycation on cancellous bone fragility. Bone 2007; 40:1144-1151.

89. Allen MR, Burr DB. Bisphosphonate effects on bone turnover, microdamage, and mechanical properties: what we think we know and what we know that we don't know. Bone 2011:49: $56-65$

90. Iwata K, Allen MR, Phipps R, Burr DB. Microcrack initiation occurs more easily in vertebrae from beagles treated with alendronate than with risedronate. Bone 2006;38(Suppl):42.

91. Bauss F, Dempster DW. Effects of ibandronate on bone quality: preclinical studies. Bone 2007:40:265-273.

92. Allen MR, Burr DB. Mineralization, microdamage, and matrix: how bisphosphonates influence material properties of bone. Bone Key Osteovision 2007;4:49-60.

93. Keaveny TM. Biomechanical computed tomography-noninvasive bone strength analysis using clinical computed tomography scans. Ann N Y Acad Sci 2010;1192:57-65.

94. Imai K, Ohnishi I, Matsumoto T, Yamamoto S, Nakamura K. Assessment of vertebral fracture risk and therapeutic effects of alendronate in postmenopausal women using a quantitative computed tomography-based nonlinear finite element method. Osteoporos Int 2009;20: 801-810.

95. Keaveny TM, Donley DW, Hoffmann PF, Mitlak BH, Glass EV, San Martin JA. Effects of teriparatide and alendronate on vertebral strength as assessed by finite element modeling of QCT scans in women with osteoporosis. J Bone Miner Res 2007:22:149-157.

96. Keaveny TM, Hoffmann PF, Singh M, Palermo L, Bilezikian JP, Greenspan SL et al. Femoral bone strength and its relation to cortical and trabecular changes after treatment with PTH alendronate, and their combination as assessed by finite element analysis of quantitative CT scans. J Bone Miner Res 2008;23:1974-1982.

97. Lewiecki EM, Keaveny TM, Kopperdahl DL, Genant HK, Engelke K, Fuerst T et al. Once-monthly oral ibandronate improves biomechanical determinants of bone strength in women with postmenopausal osteoporosis. J Clin Endocrinol Metab 2009;94:171-180.

98. Torres-Del-Pliego E, Vilaplana L, Güerri-Fernández R, Diez-Pérez A. Measuring bone quality. Curr Rheumatol Rep 2013:15:373.

99. Wu Y, Adeeb SM, Duke MJ, Munoz-Paniagua D, Doschak MR. Compositional and materia properties of rat bone after bisphosphonate and/or Strontium ranelate drug treatment. J Pharm Pharm Sci 2013;16:52-64.

100. Burket JC, Brooks DJ, MacLeay JM, Baker SP, Boskey AL, van der Meulen MC. Variations in nanomechanical properties and tissue composition within trabeculae from an ovine model of osteoporosis and treatment. Bone 2013;52:326-336.

101. Bala Y, Farlay D, Chapurlat RD, Boivin G. Modifications of bone material properties in postmenopausal osteoporotic women long-term treated with alendronate. Eur J Endocrino 2011;165:647-655

102. Peter CP, Guy J, Shea M, Bagdon W, Kline WF, Hayes WC. Long-term safety of the aminobisphosphonate alendronate in adult dogs. I. General safety and biomechanical properties of bone. J Pharmacol Exp Ther 1996;276:271-276.

103. Lafage MH, Balena R, Battle MA, Shea M, Seedor JG, Klein H et al. Comparison of alendronate and sodium fluoride effects on cancellous and cortical bone in minipigs. A one-year study. J Clin Invest 1995;95:2127-2133.

104. Toolan BC, Shea M, Myers ER, Borchers RE, Seedor JG, Quartuccio H et al. Effects of 4-amino-1-hydroxybutylidene bisphosphonate on bone biomechanics in rats. J Bone Miner Res 1992;7:1399-1406.

105. Guy JA, Shea M, Peter CP, Morrissey R, Hayes WC. Continuous alendronate treatment throughout growth, maturation, and aging in the rat results in increases in bone mass and mechanical properties. Calcif Tissue Int 1993:53:283-288.

106. Mashiba T, Turner CH, Hirano T, Forwood MR, Johnston CC, Burr DB. Effects of suppressed bone turnover by bisphosphonates on microdamage accumulation and biomechanical properties in clinically relevant skeletal sites in beagles. Bone 2001;28:524-531.

107. Allen MR, Iwata K, Phipps R, Burr DB. Alterations in canine vertebral bone turnover microdamage accumulation, and biomechanical properties following 1-year treatment with clinical treatment doses of risedronate or alendronate. Bone 2006:39:872-879.

108. Shahnazari M, Yao W, Dai W, Wang B, lonova-Martin SS, Ritchie RO. Higher doses of bisphosphonates further improve bone mass, architecture, and strength but not the tissue material properties in aged rats. Bone 2010;46:1267-1274.

109. Dempster DW. The contribution of trabecular architecture to cancellous bone quality. J Bone Miner Res 2000;15:20-23.

110. Parkinson $\mathrm{IH}$, Fazzalari NL. Interrelationships between structural parameters of cancellous bone reveal accelerated structural change at low bone volume. J Bone Miner Res 2003:18:2200-2205

111. Yeni YN, Brown CU, Wang Z, Norman TL. The influence of bone morphology on fracture toughness of the human femur and tibia. Bone 1997:21:453-459. 